\title{
The importance of indirect cues for white-browed sparrow-weaver (Plocepasser mahali) risk assessment
}

\author{
Tracy E. Fong • Travis W. DeLong • Sarah B. Hogan • \\ Daniel T. Blumstein
}

Received: 13 July 2008 /Revised: 9 March 2009 / Accepted: 16 June 2009 /Published online: 5 August 2009

(C) The Author(s) 2009. This article is published with open access at Springerlink.com

\begin{abstract}
Both direct cues that provide information about the actual presence of a predator and indirect environmental cues that provide information about the probability of encountering a predator may be used by animals assessing predation risk, but relatively few studies manipulate both simultaneously to study their relative importance. We conducted two experiments to study the foraging decisions of white-browed sparrow-weavers (Plocepasser mahali). The first experiment manipulated both direct and indirect cues in a feeding array by simultaneously placing feeding stations at different distances from humans (to manipulate direct risk) and from protective cover (to manipulate indirect risk). Weaver foraging was influenced more by indirect risk than by direct risk. The second experiment aimed to determine if weaver's indirect risk assessment was sensitive to variation in benefits. We set two feeding stations at different distances from cover but the same distance from the human observers and systematically increased the amount of food at the station farther from cover. Weavers far from cover initially foraged at higher rates than those close to cover, but the addition of food reduced the foraging rate. Together, our results illustrate that weaver foraging decisions are sensitive to variation in risk and that indirect cues are relatively more important than direct cues.
\end{abstract}

Keywords Indirect cues · Direct cues ·

Predation risk assessment

Communicated by P. Heeb

T. E. Fong · T. W. DeLong · S. B. Hogan • D. T. Blumstein $(\bowtie)$

Department of Ecology and Evolutionary Biology,

University of California,

621 Young Drive South,

Los Angeles, CA 90095-1606, USA

e-mail: marmots@ucla.edu

\section{Introduction}

We assume that the decisions that dictate how, when, and where an individual will forage are sensitive to both energetic gain and predation risk (Abrahams and Dill 1989). Animals utilize both indirect and direct cues to assess predation risk and make their foraging decisions (Grubb and Greenwald 1982; Thorson et al. 1998; Orrock et al. 2004; Schmidt 2006). Indirect cues are those environmental factors that might be somehow related to the probability of predation (Thorson et al. 1998). Direct cues are olfactory, auditory, visual, or tactile stimuli produced by a predator (Thorson et al. 1998). Compared to the number of studies that focus on a single cue (Schneider 1984; Blumstein et al. 2000; Mandelik et al. 2003; Mikheev et al. 2006), there are relatively few studies that focus on multiple cues simultaneously. Thus, how these indicators of risk interact and their relative effect in the decision-making process is relatively unknown.

A number of studies have explored the effects of direct cues on prey foraging behavior. By presenting two types of direct cues (auditory and visual), Blumstein et al. (2000) found that tammar wallabies (Macropus eugenii) were unresponsive to direct auditory cues but foraged less and looked more when exposed to direct visual cues. The importance of visual cues to elicit behavioral responses was demonstrated by Mikheev et al. (2006), who found that olfactory cues alone were not sufficient to significantly change food intake rate of juvenile perch (Perca fluviatilis), but when combined with visual presentation of the predator, food intake rate was greatly reduced. This combinatory effect demonstrates the importance of analyzing multiple features of the predator-prey system to describe the dynamic interactions that may occur. Fernandez-Juricic and Kacelnik (2003) showed that animals may use conspecific behavior to assess direct risk. 
Many studies have shown that indirect cues, such as distance to cover, can affect prey behavior. For instance, we know that cover may either be protective or obstructive. When cover is obstructive, it increases the vulnerability of foraging animals because it hinders their ability to visually detect predators (Blumstein et al. 2004; Whittingham and Evans 2004; Ebensperger and Hurtado 2005). By contrast, cover may also be protective. For instance, Schneider (1984) found that white-throated sparrows (Zonotrichia albicollis) preferentially foraged in areas closer to cover even when areas farther from cover offered greater energy intakes and only foraged in areas farther from cover when food in the area closer to cover was depleted. Similarly, Guillemain et al. (2000) showed that mallards (Anas platyrhynchos) only foraged using the riskier deep-waterdabbling method when food in the shallow mud flats, which required a less risky mud-grubbing technique, was depleted. Mandelik et al. (2003) examined the feeding behavior of the common spiny mouse (Acomys cahirinus) under the influence of two indirect cues: moonlight and overhead cover. The common spiny mouse visited fewer food patches on moonlit nights and more food patches under overhead cover instead of the open environment (Mandelik et al. 2003).

Such studies demonstrate that both direct and indirect cues may independently influence foraging behavior. However, in nature, prey often must assess the interaction and the influence of both direct and indirect cues at the same time. Thus, we must consider both simultaneously.

Indirect cues provide vital information about potential risk independently of a predator's presence. For this reason, indirect cues may provide important background information about the risk of predation, while direct cues provide information when facing an actual predator (Thorson et al. 1998). When comparing the effects of direct cues (olfactory and visual stimuli) against indirect cues (microhabitat and background coloration), Thorson et al. (1998) found that both fox squirrels (Sciurus niger) and thirteen-lined ground squirrels (Spermophilus tridecemlineatus) responded more strongly to the indirect cue of distance from refuge. Orrock et al. (2004) found that the oldfield mouse (Peromyscus polionotus) removed considerably more seeds from trays sheltered by vegetative cover and on nights where moon illumination was minimal, while they found no significant effect of predator urine (a direct cue) on mouse foraging. In contrast, Schmidt (2006) found that direct (owl vocalizations) and indirect (moonlight) cues alone had no effect, but the combination of both induced a significant reduction in movement of the white-footed mouse (Peromyscus leucopus). Given the contradictory results of these studies and the paucity of experiments that explicitly contrast the effects of direct and indirect cues on foraging behavior, further investigation is warranted.
We provided both direct and indirect cues to analyze their relative effect on the foraging behavior of the whitebrowed sparrow-weaver at the Mpala research station in Kenya. We conducted two experiments.

In the first experiment, we used a feeding array where we varied direct and indirect risk and measured the latency to initially visit a feeding plate (a demonstration of wariness), the total number of visits (a measure of preference), and the foraging behavior of those weavers who elected to forage. Given that white-browed sparrow-weavers are small social passeriformes that nest and roost in trees but forage on the ground (Ferguson and Siegfried 1989), we assumed that the cover would provide safety while foraging. Slotow and Rothstein (1995a) demonstrated that birds view adjacent vegetation as a source of protective cover from predators rather than merely as a perch. Therefore, as distance from cover increased, we predicted that perceived risk would also increase. We expected that weaver behavior would vary with this increased perception of risk such that the latency to initially visit a feeding plate would increase with increasing distance from cover, and the number of visits would decrease. We also used our presence at a specific location as a metric of direct risk. We sat quietly to simulate a stalking or waiting predator. We therefore expected that as the distance from the observer increased, the risk perceived by the weavers would decrease, and their behavior would track this decreased perception of risk. We thus predicted that latency to initially visit a feeding plate would decrease and the number of visits would increase with increasing distance from the observer.

In the second experiment, we studied whether weavers could be lured into accepting a greater indirect risk by increasing the energetic reward on a plate further from cover than one closer to cover. Since white-crowned sparrows trade off food return in the presence of predation risk (Slotow and Paxinos 1997), we predicted that indirect risk would influence behavior and that weavers would trade off cost of predation risk with benefit of extra food. While similar studies have been performed with respect to direct and indirect cues (Lima 1990; Thorson et al. 1998), few have integrated quantitative measures (latency, duration, and number of visits) with behavior (vigilance, foraging, and vocalizing). Combining these two methods to quantify behavior provides further insight into the decision-making process under both direct and indirect predation risk. Thus, our study comprehensively explores the reliability of indirect versus direct cues and how they interact to influence the foraging behavior of a granivorous passerine.

\section{Materials and methods}

In October 2007, from 0630 to 1800 hours, we established feeding arrays in a $20 \times 20$-m portion of a large meadow at 
the Mpala Research Station in the Laikipia District of Kenya $\left(36^{\circ} 54^{\prime} \mathrm{E}, 0^{\circ} 17^{\prime} \mathrm{N}\right)$. Our study site was bordered on the eastern side by a line of trees approximately $5 \mathrm{~m}$ tall that provide protective cover to the weavers, and we assumed that the distance from cover would be perceived as an indirect cue of risk. We assumed that the cover was perceived as a safe location because it did not inhibit visibility significantly and thus served as an effective refuge (Caro 2005). Two observers sat, quietly, at one edge of the feeding array, and we assumed that the distance from the human observers would be perceived as a direct cue of risk (Caro 2005). We focused on white-browed sparrowweavers, social birds that live in groups of two to 11 individuals (Collias and Collias 1978; Lewis 1982). We note that weavers at this site did not normally land next to humans, and they flushed when we approached them. Thus, while they may have been somewhat habituated, they still responded fearfully to humans. Our study site contained one colony of ten to 15 weavers; strictly our inferences are limited to this colony. Weavers from this colony were not color-ringed for individual identification.

\section{Experiment 1}

Data were collected over 5 days. Observations for the first three trials were made from 0630 to 1800 hours, and for trials four and five, observations were made from 0630 to 1000 hours. Observations were made by two individuals at a time (observers rotated every $4 \mathrm{~h}$ ). We trained (with other birds) until we were consistently recording data. Our experimental array consisted of three rows, each with four $26-\mathrm{cm}$ diameter white plastic plates. The three rows were arranged along a bias so that they were exactly 5,10 , and $15 \mathrm{~m}$ away from the observers, and each plate within the row was $0,5,10$, or $15 \mathrm{~m}$ away from cover. The human observers sat $7.5 \mathrm{~m}$ west of the tree line on the southern side of the array.

We placed a handful of sorghum in each plate and refilled the plate whenever depleted. The plates were large enough to allow for more than one white-browed sparrowweaver to forage simultaneously, which occurred often. Weavers readily foraged on sorghum.

Each visit to a plate was recorded. We noted the plate visited, the weaver's arrival time to the plate, their latency to forage once they landed on the plate, and their time of departure. We also noted if other conspecifics were present on the plate. If an individual visited more than one plate during a foray into the array, each landing at a plate was scored separately. When weavers were on plates, we conducted focal observations with continuous recording to quantify time allocation (Martin and Bateson 1993). We dictated into a microcassette recorder the onset of each bout of foraging (head down and pecking at plate), vigilance (head elevated and neck stretched), calling (weavers produced food calls when they discovered food; Valone 1996), grooming (pecking at feathers), hopping (jumping to and from plates and within study site), and when they were off the plate.

We graphically examined the number of visits to each plate and the latency for any weaver to initially visit each plate. Focal observations were analyzed using JWatcher 1.0 (Blumstein et al. 2006). After visually examining our data, we elected to focus our formal analyses on foraging rate and vigilance rate, because previous studies have demonstrated that these behaviors are sensitive to variation in predation risk (Slotow and Rothstein 1995b; Slotow and Coumi 2000). We fitted two-way general linear models in Statistical Package for the Social Sciences (SPSS) version 14 (SPSS 2005) to examine effects of indirect risk, direct risk, and their interaction on time allocation. We calculated partial $\eta^{2}$ values and used them as our estimate of effect size, and we report $R^{2}$ values for the models.

\section{Experiment 2}

We attempted to find the amount of food that would cause the weavers to forage farther from cover (Lima and Bednekoff 1999; Brown and Kotler 2004; Slotow and Paxinos 1997). We collected data over 4 days. The first and second trials took place from 1400 to 1800 hours on days 1 and 2, the third from 1400 to 1800 hours on day 3 , and the fourth and fifth trials from 0600 to 1000 and 1400 to 1800 hours on day 4 . We placed two plates $10 \mathrm{~m}$ away from the observers; the first plate was placed $0 \mathrm{~m}$ from cover, and the second plate was placed $15 \mathrm{~m}$ from cover. For the first trial, we placed $4 \mathrm{~g}$ of sorghum on each plate and replenished the sorghum when necessary. For the second trial, we placed $4 \mathrm{~g}$ of sorghum on the $0-\mathrm{m}$ plate and $8 \mathrm{~g}$ of sorghum on the $15-\mathrm{m}$ plate. For the third trial, we placed $4 \mathrm{~g}$ of sorghum on the $0-\mathrm{m}$ plate and $16 \mathrm{~g}$ of sorghum on the $15-\mathrm{m}$ plate. For the fourth trial, we placed $4 \mathrm{~g}$ of sorghum on the $0-\mathrm{m}$ plate and $32 \mathrm{~g}$ of sorghum on the $15-\mathrm{m}$ plate. As in experiment 1 , we conducted focal observations of foraging weavers, scored these focals using JWatcher 1.0, and analyzed the data with two-way analysis of variance models.

\section{Results}

\section{Experiment 1}

There were 383 weaver visits during experiment 1 . Several lines of evidence suggest that weavers were more sensitive to indirect risk than to direct risk. Weaver visits to plates were not random $\left(\chi^{2}=38.817, d f=6, p<0.0001\right)$; they 
visited plates more if they were closer to cover than farther from cover, but there was no relationship between distance to the observer and the number of weaver visits (Fig. 1). Additionally, plates closer to cover tended to be first visited sooner than plates farther from cover, but again, there was no relationship as a function of distance to observer (Fig. 2).

Perhaps the most compelling evidence for the importance of indirect risk comes from the results of our focal observations. Variation in foraging rate was significantly ( $\left.p=0.047, \eta^{2}=0.061\right)$ explained by indirect risk, though not by direct risk $\left(p=0.520, \eta^{2}=0.010\right.$; Table 1$)$. In general, we noted that foraging rate increased with increasing distance to cover. The indirect, but not direct risk, significantly ( $p=$ $0.008, \eta^{2}=0.089$ ) explained variation in vigilance rate. As weavers foraged farther from cover, they increased their vigilance rate. Moreover, the effect size of indirect risk, while small $\left(\eta^{2}=0.089\right)$, was four times that of direct risk $\left(\eta^{2}=0.022\right)$. For vigilance rate, there was no significant interaction $\left(p=0.263, \eta^{2}=0.058\right)$ between direct and indirect risk.

\section{Experiment 2}

There were 77 weaver visits during the course of our feeding manipulation. We found a significant effect of indirect risk on foraging rate $\left(p=0.026, \eta^{2}=0.069\right)$ and a significant effect of food at $15 \mathrm{~m}$ on foraging rate $(p=$ $0.003, \eta^{2}=0.179$; Fig. 3a). Weavers foraged at faster rates when farther from cover and foraged at slower rates when

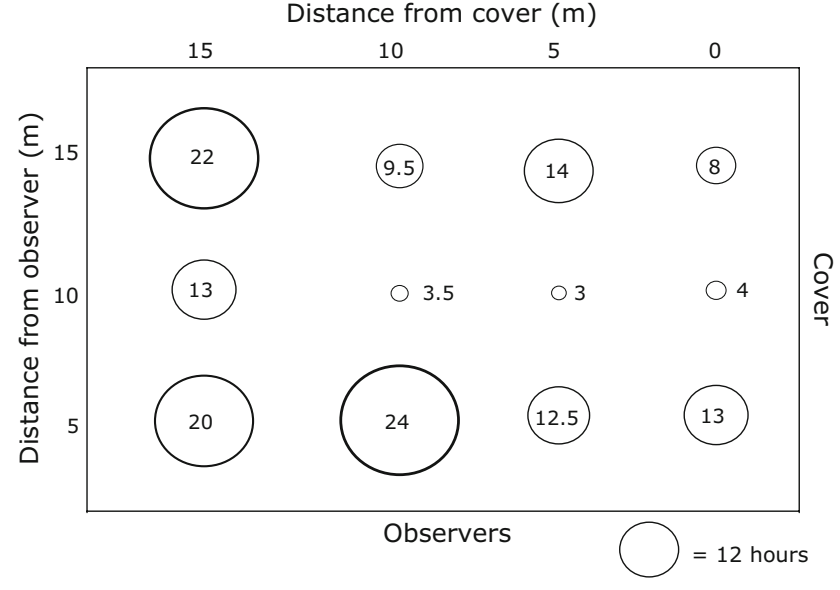

Fig. 2 The latency to arrive at each plate scaled by circle size in experiment 1 . Circles represent the average number of hours during the time which plates were set up that it took for weavers to first visit the plate. Thus, latencies $>12 \mathrm{~h}$ means that it took more than one experimental (12-h) day for an individual to first visit a plate. Plates closer to cover were visited by weavers sooner than plates farther from cover. There was no obvious relationship in latency to arrive as a function of distance to the observer

there was more food provided at the $15-\mathrm{m}$ plate. There was no significant interaction between indirect risk and food at the $15-\mathrm{m}$ plate $\left(p=0.964, \eta^{2}=0.001\right)$, and the model significantly $\left(p=0.004, \eta^{2}=0.236\right)$ explained $17 \%$ of the variation in foraging rate. No significant effect of either indirect risk or food at the $15-\mathrm{m}$ plate was found for vigilance rates (Fig. 3b).

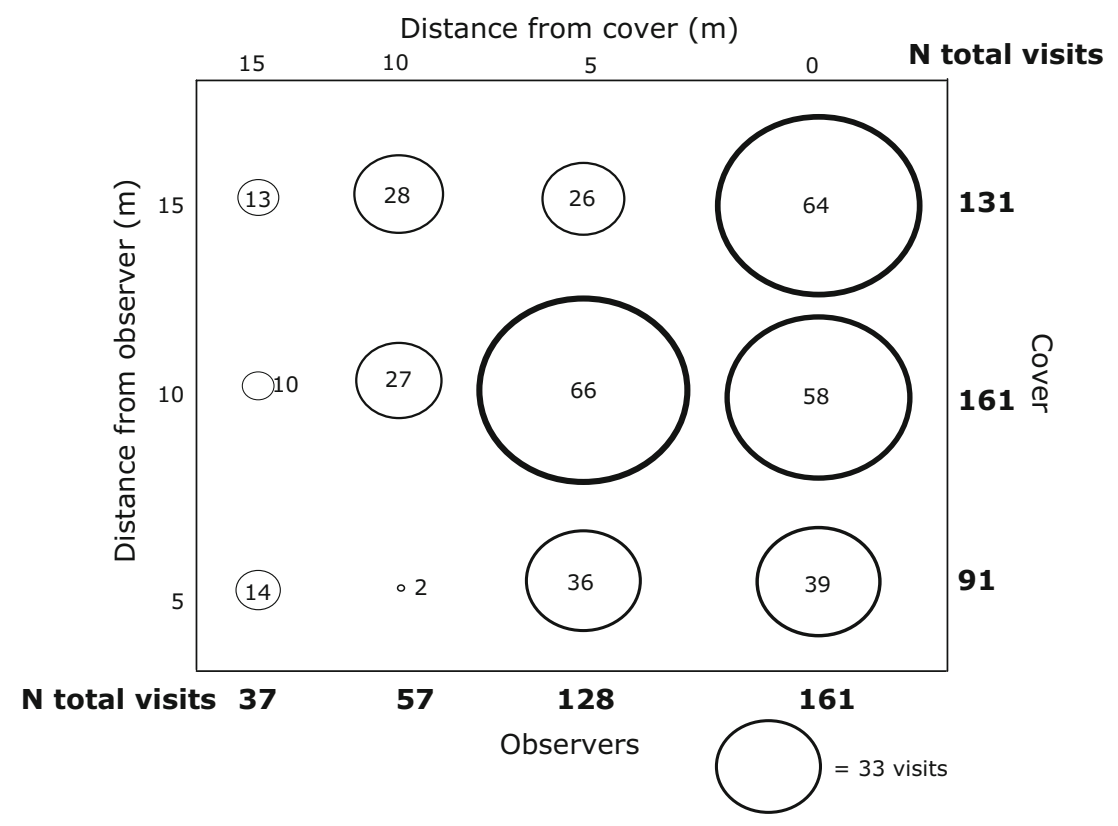

Fig. 1 The number of visits (represented by relative circle size) to each plate by weavers in experiment 1 . Visits were non-randomly distributed $\left(\chi^{2}=38.817, d f=6, p<0.0001\right)$, with plates closer to cover receiving more visits by weavers than plates farther from cover. There was no relationship in total number of visits as a function of distance to the observer 
Table 1 Results ( $B$ values, $p$ values, and partial $\eta^{2}$ ) of general linear model examining the effects of direct and indirect risk on foraging and vigilance rates of 139 white-browed sparrow-weaver visits to an artificial feeding array

\begin{tabular}{|c|c|c|c|c|}
\hline & & $B$ & $p$ & $\eta^{2}$ \\
\hline \multirow[t]{12}{*}{ Foraging rate } & Corrected model & & 0.123 & 0.118 \\
\hline & Intercept & 52.486 & $<0.001$ & 0.916 \\
\hline & Direct risk & & 0.52 & 0.01 \\
\hline & $5 \mathrm{~m}$ & 2.869 & 0.632 & \\
\hline & $10 \mathrm{~m}$ & 8.917 & 0.178 & \\
\hline & $15 \mathrm{~m}$ & & & \\
\hline & Indirect risk & & 0.047 & 0.061 \\
\hline & $0 \mathrm{~m}$ & & & \\
\hline & $5 \mathrm{~m}$ & 9.271 & 0.169 & \\
\hline & $10 \mathrm{~m}$ & 1.937 & 0.788 & \\
\hline & $15 \mathrm{~m}$ & 18.389 & 0.031 & \\
\hline & $\begin{array}{l}\text { Direct risk } \times \\
\text { indirect risk }\end{array}$ & & 0.072 & 0.086 \\
\hline \multirow[t]{12}{*}{ Vigilance rate } & Corrected model & & 0.08 & 0.128 \\
\hline & Intercept & 44.357 & $<0.001$ & 0.943 \\
\hline & Direct risk & & 0.237 & 0.022 \\
\hline & $5 \mathrm{~m}$ & 5.157 & 0.212 & \\
\hline & $10 \mathrm{~m}$ & 4.993 & 0.272 & \\
\hline & $15 \mathrm{~m}$ & & & \\
\hline & Indirect risk & & 0.008 & 0.089 \\
\hline & $0 \mathrm{~m}$ & & & \\
\hline & $5 \mathrm{~m}$ & 5.746 & 0.215 & \\
\hline & $10 \mathrm{~m}$ & 3.744 & 0.450 & \\
\hline & $15 \mathrm{~m}$ & 10.983 & 0.061 & \\
\hline & $\begin{array}{l}\text { Direct risk } \times \\
\text { indirect risk }\end{array}$ & & 0.263 & 0.058 \\
\hline
\end{tabular}

Coefficients for direct and indirect risk are, with tested against a reference, $15 \mathrm{~m}$ row for direct and $0 \mathrm{~m}$ from cover for indirect

\section{Discussion}

Taken together, our results strongly suggest that whitebrowed sparrow-weaver foraging behavior is influenced by indirect cues of predation risk. Weaver patch choice could be manipulated by food addition suggesting that benefits influence foraging decisions. Additionally, weavers foraged the most at feeding plates closer to cover, took the longest time to arrive at plates farthest from cover, and had higher rates of foraging and vigilance when farther from cover.

Conducting both experiments in the same area may have increased the likelihood of a single weaver visiting the food plates numerous times, and thus potentially allowing the weavers to habituate to humans. If so, it is conceivable that weavers at the research center did not view humans as a sufficient threatening stimulus. However, as we noted in the introduction, weavers did not land near us if there was no food, and they flushed when we approached them. Thus, we do not infer that they had no fear of humans, and thus humans are conceivably a relevant threatening stimulus. It would be interesting to see if other predators (e.g., felids) sitting at the same distance from the array generated different results. Future experiments could study this.

Our results suggest that once weavers elected to forage on our array, they were more sensitive to the indirect cue than the direct cue. However, the lack of a strong direct effect and a relatively strong indirect effect could be explained by the weavers having assessed that there was limited danger associated with our presence, while risk associated with the indirect cue remained unchanged. Viewed this way, direct cues quickly provide information about risk and permit animals to dynamically modify their assessment. In some cases, this may mean that animals may appear unaffected by a direct cue. By contrast, indirect cues, because they are indirect, provide more probabilistic information about risk and help minimize the risk of encountering a predator (Thorson et al. 1998). The information about risk contained in an indirect cue does not get updated as quickly; being vigilant at the plates and cover does not help an individual assess the probability of

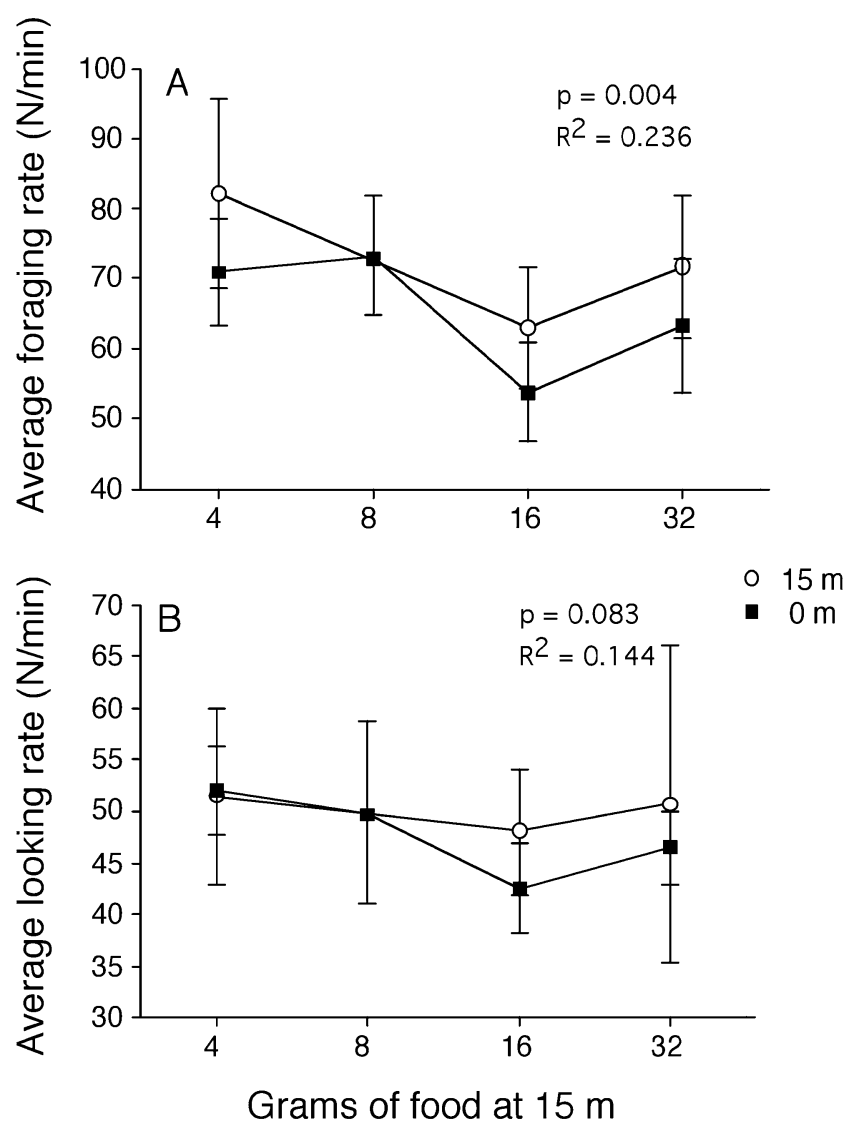

Fig. 3 The effect of food supplementation at the distant plate on: (a) mean $( \pm 95 \% \mathrm{CI})$ foraging rate and (b) mean $( \pm 95 \% \mathrm{CI})$ vigilance rate 
surviving an attack. Additionally, prey may have more than a single predator, and Orrock et al. (2004) noted the greater importance of indirect cues than direct cues for prey with multiple predators.

We may also expect some interaction between direct and indirect cues. Brinkerhoff et al. (2005) found that predator urine and microhabitat had a combined effect on the foraging behavior of small mammals. Kotler et al. (1991) studied the foraging behavior of two species of gerbils (Gerbillus allenbyi and Gerbillus pyramidium) when owls were present and absent in conjunction with varying microhabitat features and illumination levels. They found a combined effect of these three indirect and direct variables. Thus, direct cues may provide important information about risk in the context of specific indirect cues. Further analyses of the relative effect sizes of both direct and indirect cues when simultaneously considered could elucidate their relative importance in a system where both cues influence foraging behavior but to different extents.

The relatively small effect sizes for significant results imply that other factors besides perceived risk influenced foraging behavior. We acknowledge that while weavers are seed-eaters, our choice of only providing sorghum may have influenced foraging behavior; providing mixed diets may increase foraging time (e.g., Randolph and Cameron 2001). Heterospecific competitors may also influence foraging behavior (e.g., Alatalo and Moreno 1987), and there were occasional visits by other granivorous birds to our array. Furthermore, intraspecific competition among the weavers may influence their foraging behavior. Previous studies have shown that aggression among individuals of the same species increases with increasing group size when individuals are at safer foraging locations (Slotow and Rothstein 1995b; Slotow and Coumi 2000; Slotow 1996). Environmental conditions could potentially influence foraging decisions. Although the weather was fairly consistent throughout our sampling period, when it was very hot or very windy, weavers did not forage. Slotow and Coumi (2000) also considered the effect of temperature on foraging distance in their study on the vigilance of bronze mannikin (Lonchura cucullata) groups. Formally, we did not quantify temperature, but (aside from animals not foraging during the heat of the day) we detected no obvious effects of temperature on risk taking.

Despite the relatively small effect sizes, our results are consistent: white-browed sparrow-weavers varied their foraging behavior in response to indirect cues normally associated with predation risk. Because the risk estimated by such indirect cues may not change over time, indirect cues may be generally more important for long-term assessments that individuals make about where, when, and how to forage, while direct cues may be relatively more important in deciding whether to forage in the first place.
Acknowledgements We are extremely thankful to Director Margaret Kinnaird, Christopher Odhiambo, and the staff of Mpala who welcomed us and facilitated our work, and Mathew Namoni and Lucretia Olson for help in the field and laboratory. We thank the Kenyan Ministry of Science and Technology for permission to work at Mpala, and the UCLA Department of Ecology and Evolutionary Biology, the UCLA Office of Instructional Development, and the Lida Scott Brown Endowment for partial support. Constructive comments from two anonymous reviewers helped us clarify our message.

Open Access This article is distributed under the terms of the Creative Commons Attribution Noncommercial License which permits any noncommercial use, distribution, and reproduction in any medium, provided the original author(s) and source are credited.

\section{References}

Abrahams MV, Dill LM (1989) A determination of the energetic equivalence of the risk of predation. Ecology 70:999-1007. doi: $10.2307 / 1941368$

Alatalo RV, Moreno J (1987) Body size, interspecific interactions, and use of foraging sites in tits (Paridae). Ecology 68:1773-1777. doi: $10.2307 / 1939868$

Blumstein DT, Daniel JC, Griffin AS, Evans CS (2000) Insular tammar wallabies respond to visual but not acoustic cues from predators. Behav Ecol 11:528-535. doi:10.1093/beheco/ 11.5.528

Blumstein DT, Runyan A, Seymour M, Nicodemus A, Ozgul A, Ransler F, Im S, Stark T, Zugmeyer C, Daniels JC (2004) Locomotor ability and wariness in yellow-bellied marmots. Ethology 110:615-634. doi:10.1111/j.1439-0310.2004.01000.x

Blumstein DT, Daniel JC, Evans CS (2006) JWatcher 1.0 http://www. jwatcher.ucla.edu

Brinkerhoff RJ, Haddad NM, Orrock JL (2005) Corridors and olfactory predator cues affect small mammal behavior. J Mammal 86:662-669. doi:10.1644/1545-1542(2005)086[0662:CAOPCA] 2.0.CO;2

Brown JS, Kotler BP (2004) Hazardous duty pay and the foraging cost of predation. Ecol Lett 7:999-1014. doi:10.1111/j.14610248.2004.00661.x

Caro T (2005) Antipredator defenses in birds and mammals. University of Chicago Press, Chicago

Collias NE, Collias EC (1978) Cooperative breeding behavior in the white-browed sparrow weaver. Auk 95:472-484

Ebensperger LA, Hurtado MJ (2005) On the relationship between herbaceous cover and vigilance activity of degus (Octodon degus). Ethology 111:593-608. doi:10.1111/j.14390310.2005.01084.x

Ferguson JWH, Siegfried WR (1989) Environmental factors influencing nest-site preference in white-browed sparrow-weavers (Plocepasser mahali). Condor 91:100-107. doi:10.2307/1368152

Fernandez-Juricic E, Kacelnik A (2003) Information transfer and gain in flocks: the effects of quantity of social information at different neighbor distances. Behav Ecol Sociobiol 55:502-511. doi:10.1007/s00265-003-0698-9

Grubb TC, Greenwald L (1982) Sparrows and a brushpile: foraging responses to different combinations of predation risk and energy cost. Anim Behav 30:637-640. doi:10.1016/S0003-3472(82) 80133-4

Guillemain M, Fritz H, Blais S (2000) Foraging methods can affect patch choice: an experimental study in mallard (Anas platyrhynchos). Behav Processes 50:123-129. doi:10.1016/S0376-6357 (00)00095-4 
Kotler BP, Brown JS, Hasson O (1991) Factors affecting gerbil foraging behavior and rates of owl predation. Ecology 72:2249 2260. doi: $10.2307 / 1941575$

Lewis D (1982) Cooperative breeding in a population of whitebrowed sparrow weavers (Plocepasser mahali). Ibis 124:511522. doi:10.1111/j.1474-919X.1982.tb03795.x

Lima SL (1990) Protective cover and the use of space-different strategies in finches. Oikos 58:151-158. doi:10.2307/3545422

Lima SL, Bednekoff PA (1999) Temporal variation in danger drives antipredator behavior: the predation risk allocation hypothesis. Am Nat 153:649-659. doi:10.1086/303202

Mandelik Y, Jones M, Dayan T (2003) Structurally complex habitat and sensory adaptations mediate the behavioural responses of a desert rodent to an indirect cue for increased predation risk. Evol Ecol Res 5:501-515

Martin P, Bateson P (1993) Measuring behavior: an introductory guide, 2nd edn. Cambridge University Press, Cambridge

Mikheev VN, Wanzenbock J, Pasternak AF (2006) Effects of predator-induced visual and olfactory cues on $0+$ perch (Perca fluviatilis L.) foraging behaviour. Ecol Freshw Fish 15:111-117. doi:10.1111/j.1600-0633.2006.00140.x

Orrock JL, Danielson BJ, Brinkerhoff RJ (2004) Rodent foraging is affected by indirect, but not by direct cues of predation risk. Behav Ecol 15:433-437. doi:10.1093/beheco/arh031

Randolph JC, Cameron GN (2001) Consequences of diet choice by a small generalist herbivore. Ecol Monogr 71:117-136

Schmidt KA (2006) Non-additivity among multiple cues of predation risk: a behaviorally-driven trophic cascade between owls and songbirds. Oikos 113:82-90. doi:10.1111/j.0030-1299.2006.14167.x
Schneider KJ (1984) Dominance, predation, and optimal foraging in white-throated sparrow flocks. Ecology 65:1820-1827. doi: $10.2307 / 1937778$

Slotow R (1996) Aggression in white-crowned sparrows increases at safer foraging locations and with increasing group size. Condor 98:245-252. doi:10.2307/1369142

Slotow R, Coumi N (2000) Vigilance in bronze manikin groups: the contributions of predation risk and competition. Behaviour 137:565-578. doi:10.1163/156853900502213

Slotow R, Paxinos E (1997) Intraspecific competition influences the food return-predation risk trade-off by white-crowned sparrows. Condor 99:642-650. doi:10.2307/1370476

Slotow R, Rothstein SI (1995a) The importance of cover and the effect of social rank on foraging white-crowned sparrows: an experiment with an artificial shrub. Auk 112:107-117

Slotow R, Rothstein SI (1995b) Influence of social status, distance from cover, and group size on feeding and vigilance in whitecrowned sparrows. Auk 112:1024-1031

SPSS (2005) SPSS user's manual. Release 14.0. SPSS, Chicago, IL

Thorson JM, Morgan RA, Brown JS, Norman JE (1998) Direct and indirect cues of predatory risk and patch use by fox squirrels and thirteen-lined ground squirrels. Behav Ecol 9:151-157. doi:10.1093/beheco/9.2.151

Valone TJ (1996) Food-associated calls as public information about patch quality. Oikos 77:153-157. doi:10.2307/3545595

Whittingham MJ, Evans KL (2004) The effects of habitat structure on predation risk of birds in agricultural landscapes. Ibis 146:210 220. doi:10.1111/j.1474-919X.2004.00370.x 